\title{
The effect of 8 years of strict glycaemic control on peripheral nerve function in IDDM patients: the Oslo Study
}

\author{
K.-F. Amthor ${ }^{1}$, K. Dahl-Jørgensen ${ }^{2}$, T.J. Berg ${ }^{2}$, M.Skard Heier ${ }^{3}$, L. Sandvik ${ }^{4}$, Ø. Aagenæs ${ }^{2}$, K. F.Hanssen ${ }^{2}$ \\ ${ }^{1}$ Department of Neurology, Ullevål University Hospital, Oslo, Norway \\ ${ }^{2}$ Aker Diabetes Research Center, Aker University Hospital, Oslo, Norway \\ ${ }^{3}$ Department of Clinical Neurophysiology, Ullevål University Hospital, Oslo, Norway \\ ${ }^{4}$ Medstat Ltd., Oslo, Norway
}

\begin{abstract}
Summary We have investigated the effect of long-term strict glycaemic control on peripheral and autonomic nerve function in 45 IDDM patients (age 18-42 years, diabetes duration 7-23 years) without clinical signs of neuropathy or other neurological disease. They were randomly assigned to treatment either with continuous insulin infusion, multiple injections (4-6 times daily), or conventional treatment (twice daily) for 4 years and followed prospectively for 8 years. Motor and sensory nerve conduction velocities were measured at the start and after 8 years. Autonomic nerve function tests were performed only once, after 8 years. A significant reduction of nerve conduction velocity was observed during 8 years in patients with mean $\mathrm{HbA}_{1}$ more than $10 \%$ ( $n=12$, group mean $10.9 \%$, range $10.1-13.2 \%$ ) compared to patients with $\mathrm{HbA}_{1}$ less than $10 \%(n=33$, group mean $9.0 \%$, range $7.5-9.9 \%$ ). Change of motor nerve conduction velocity in the peroneal nerve was: $-4.8 \pm 4.9$ (SD) vs $-2.2 \pm 5.3 \mathrm{~m} / \mathrm{s}(p<0.01)$. Change of
\end{abstract}

Polyneuropathy is a common complication of diabetes mellitus which may affect somatic and autonomic parts of the peripheral nervous system. The pathogenesis of diabetic neuropathy is still not clear. Chronic hyperglycaemia with its metabolic consequences may be the most important factor [1-5]. There is evidence that microvascular complications such as nephropathy and retinopathy may be retarded by strict glycaemic control

Received: 12 July 1993

and in revised form: 14 December 1993

Corresponding author: Dr. K. Dahl-Jørgensen, Aker Diabetes Research Center, Aker University Hospital, N-0514 Oslo, Norway

Abbreviations: IDDM, Insulin-dependent diabetes mellitus motor nerve conduction velocity in the posterior tibial nerve was: $-6.8 \pm 5.7 \mathrm{vs}-3.9 \pm 5.1 \mathrm{~m} / \mathrm{s}(p<0.05)$. No significant changes were observed in the ulnar nerve. Change of sensoric nerve conduction velocity in the sural nerve was: $-8.9 \pm 8.0$ vs $-4.6 \pm 5.3 \mathrm{~m} / \mathrm{s}(p<0.05)$. Multiple regression analysis showed that a change in $\mathrm{HbA}_{1}$ of $1 \%$ resulted in a $1.3 \mathrm{~m} / \mathrm{s}$ change in nerve conduction velocity during 8 years. A significantly lowered heart-rate variation during deep breathing $(p<0.05)$ and heart-rate response to standing $(p<0.01)$ was found in patients with $\mathrm{HbA}_{1}$ more than $10 \%$ compared to patients with $\mathrm{HbA}_{1}$ less than $10 \%$. This study confirms that the long-term lowering of blood glucose retards the deterioration in nerve conduction velocity observed in the diabetic nerve. [Diabetologia (1994) 37: 579-584]

Key words IDDM, nerve conduction velocity, neuropathy, intensified insulin treatment.
[6-9]. It is however still uncertain whether strict control of hyperglycaemia can prevent the occurrence and progression of polyneuropathy in patients with long-standing diabetes $[10,11]$. Several short-term studies have demonstrated improvement of nerve conduction velocity in newly-diagnosed patients undergoing intensive insulin injection therapy [12-14] and in patients treated with continuous subcutaneous insulin infusion [15-18].

In a previous study we demonstrated using frequent nerve conduction velocity measurements improvement after 2 years of continuous subcutaneous insulin infusion [19]. The aim of the present investigation was to study whether long-term near-normoglycaemia might influence the progression of asymptomatic diabetic neuropathy. We report the results of the same patients followed-up prospectively for 8 years. 


\section{Subjects and methods}

In 198245 IDDM were included in the Oslo study [19]. The protocol was approved by the Ethical Committee of the Norwegian Council for Science and the Humanities.

The patients fulfilled the following criteria: age between 18 and 45 years, diagnosis of diabetes before 30 years of age, duration of disease more than 7 but less than 30 years, no clinical signs of nephropathy (serum creatinine $<150 \mu \mathrm{mol} / 1$ ) or systematic hypertension (diastolic blood pressure less than $100 \mathrm{~mm} \mathrm{Hg}$ ), no proliferative retinopathy, not pregnant, negative for C-peptide (less than $0.1 \mathrm{nmol} / 16 \mathrm{~min}$ after administration of $1 \mathrm{mg}$ glucagon i. v.), and using no medication other than insulin apart from the oral contraceptive. There was no evidence of alcohol abuse in any of the patients. Two patients had intermittent proteinuria during the prestudy-period. Eleven patients had no retinopathy, $34 \mathrm{had}$ simplex retinopathy. A general neurological examination was performed which showed that the patients had no clinical signs of neuropathy or other neurological diseases. We did not however use a detailed symptom questionnaire. One patient in each treatment group had a reduced nerve conduction velocity and sensory nerve action potential amplitude in their sural nerves. Thirteen patients (four on continuous subcutaneous insulin infusion, five on multiple injections, and four on conventional treatment) had one single nerve conduction velocity measurement slightly below the normal range initially. Otherwise, normal values were found. One patient at entry to the study was taking furosemid and angiotensin converting enzyme inhibitor due to hypertension. One patient was not available for reinvestigation in 1990. In this case the nerve conduction velocity measurements of the 2-year followup examination were used in the statistical analysis.

Before starting the study all patients were treated with two daily injections of insulin. Baseline results were obtained during a 2-month prestudy-period with home blood glucose monitoring. According to the study design the patients were randomly assigned to three different modes of treatment: continuous subcutaneous insulin infusion with portable pumps, multiple injections by means of insulin pens (Novo Nordisk, Bagsvaerd, Denmark), or continued conventional treatment with two daily injections of individually mixed rapid and NPH insulins. In the multiple injection group rapid acting insulin was injected before each meal (4-6 times daily) and NPH insulin given at bedtime. Continuous subcutaneous insulin infusion and multiple injections were started and optimized during a 5-day stay in the Diabetes Unit, Department of Medicine. The patients were followed-up by the same two investigators in the out-patient clinic. The first year of the study period the patients were seen monthly and in the following years every third month for the remainder of the study period. Due to the favourable results obtained by intensified insulin treatment after 4 years, the patients could freely choose the mode of treatment from that time [19]. Ten patients continued treatment with continuous subcutaneous insulin infusion, two with two daily injections and 33 with multiple injections, which is now the preferred treatment of IDDM in Norway.

Laboratory examinations. Blood glucose control was monitored by measuring stable glycated haemoglobin $\left(\mathrm{HbA}_{1}\right.$, reference values 5.4 to $7.6 \%$, interassay coefficient of variation less than $5 \%$ ) at each visit. The mean of all measurements after randomization was used for statistical analysis. The patients performed home blood glucose monitoring by means of Haemoglucotest 1 44 regularly. After the second year these results were not systematically reported.

Neurophysiological examinations. Motor nerve conduction velocities and F-responses were measured in the right ulnar, pero- neal and tibial nerves. F-response latency was measured as the shortest latency of 10 consecutive responses. Sensory nerve conduction and response amplitudes were measured in the ulnar and sural nerves. Nerve stimulation was applied percutaneously with a bipolar surface electrode. Both motor responses and sensory nerve responses were recorded with surface electrodes. DISA electronic Ltd. (Skovlunde, Denmark) Neuromatic electromyography equipment was used. Coefficient of variation of nerve conduction velocity is $5-10 \%$. The examination was performed by two experienced neurophysiologists using standardized methods. Skin temperature was kept above $32^{\circ} \mathrm{C}$ registered by a thermistor.

Autonomic nerve function tests included beat-to-beat heart-rate variation during deep breathing ( $\mathrm{R}-\mathrm{R}$ variation), heart rate variation during a standardized Valsalva manoeuvre (Valsalva ratio) and postural heart rate response (15:0 ratio and $30: 15$ ratio). These tests were performed as described by Ewing and Clarke [20]. The Valsalva manoeuvre was avoided in patients with proliferative retinopathy, because of the risk of retinal haemorrhage. Autonomic tests were performed after 8 years only.

\section{Statistical analysis}

To decide whether the relation between mean $\mathrm{HbA}_{1}$ and a response variable (e.g. change in nerve conduction velocity during 8 years) was statistically significant, a one-sided Wilcoxon ranksum test was used, comparing the responses in the group of patients with mean $\mathrm{HbA}_{1}$ greater than $10 \%$ with the responses in the group of patients with mean $\mathrm{HbA}_{1}$ less than $10 \%$. When simultaneously studying the relation between a response variable and several potential predictors of this response variable, multiple regression analysis was applied, with the response variable as the dependent variable, and the "potential predictors" (e.g. age, sex, mean $\mathrm{HbA}_{1}$ ) as independent variables. A significance level of $5 \%$ was applied.

\section{Results}

Blood glucose control. The mean $\mathrm{HbA}_{1}$ level of the patients through 8 years was significantly reduced compared to the level at inclusion. The mean $\mathrm{HbA}_{1}$ was 11.2 (2.2)\% (SD) (range 7.5-18.9) at start, and the mean of all measurements during the 8-year follow-up period was $9.5(1.5) \%$ (range $7.5-13.2 \%$ ), a significant longterm improvement $(p<0.001)$. No upward drift of $\mathrm{HbA}_{1}$ was observed over time when the patients could freely choose mode of treatment after 4 years of strict randomization. Clinical data at the start of the study and after the 8-year follow-up are presented in Table 1. A significant rise of blood pressure $(p=0.002)$, worsening of retinopathy $(p=0.005)$ and increase of urinary albumin excretion $(p=0.02)$ was found in the group of patients with $\mathrm{HbA}_{1}$ greater than $10 \%[6,7]$. One patient received anti-hypertensive medication during the last 4 years.

Neurophysiological findings. A general reduction of nerve conduction velocity, inversely related to the degree of glycaemic control was observed at the 8-year 
follow-up examination. Grouping the patients according to mean 8-years $\mathrm{HbA}_{1}$ in three groups with $\mathrm{HbA}_{1}$ less than $9 \%(n=20), \mathrm{HbA}_{1} 9.1-10 \%(n=13)$ and $\mathrm{HbA}_{1}$ greater than $10 \%(n=12)$, the latter group showed a significant reduction of motor and sensory nerve conduction velocities and increase of F-response

Table 1. Clinical characteristics of 45 diabetic patients at baseline and at the 8-year follow-up

\begin{tabular}{llll}
\hline & Baseline & 8 years & $p$ value \\
\hline Age (years) & $26(18-36)$ & $34(26-44)$ & \\
$\begin{array}{l}\text { Duration (years) } \\
\begin{array}{l}\text { Systolic blood } \\
\text { pressure (mm Hg) }\end{array}\end{array}$ & $12.8(6-23)$ & $20.7(14-32)$ & \\
$\begin{array}{l}\text { Diastolic blood } \\
\text { pressure (mm Hg) }\end{array}$ & $81(70-95)$ & $81(60-100)$ & 0.86 \\
$\begin{array}{l}\text { Urinary albumin } \\
\text { excretion (mg/24 h) }\end{array}$ & $20.0(2-523)$ & $53.0(1-409)$ & 0.5 \\
$\begin{array}{l}\text { Severity of } \\
\text { retinopathy }\end{array}$ & $17(0-154)$ & $45(0-200)$ & 0.005 \\
\hline
\end{tabular}

${ }^{a}$ Counts of microaneurysms and haemorrhages (both eyes). Values are mean (range) latencies in the lower limb (Fig. 1, Table 2). Changes were most pronounced in the sural nerve. Deterioration of nerve conduction velocity and F-response latency in the upper limb did not reach statistical significance.

There was a reduction of 2.3 micro $\mathrm{V}$ (from 7.7 (4.0) (SD) to 5.4 (4.1)) of the sensory nerve action potential amplitude of the sural nerve in the group of patients with $\mathrm{HbA}_{1}$ over $10 \%$. No changes of sensory nerve action potential amplitudes were found in the groups of patients with $\mathrm{HbA}_{1}$ less than $10 \%$. The difference between these groups was significant $(p<0.05)$.

A multiple regression analysis was made to evaluate the relative influence of clinical background data such as age, sex, duration of diabetes, initial $\mathrm{HbA}_{1}$, and mean $\mathrm{HbA}_{1}$ on nerve conduction velocity after 8 years. The analysis showed that mean $\mathrm{HbA}_{1}$ during 8 years was the only parameter of statistical significance. A $1 \%$ difference of $\mathrm{HbA}_{1}$ was associated with a $1.2 \mathrm{~m} / \mathrm{s}$ change of nerve conduction velocity in the peroneal nerve $(p=0.01)$ in 8 years. The corresponding values were 1.3 $\mathrm{m} / \mathrm{s}$ in the posterior tibial $(p=0.009)$ and $1.4 \mathrm{~m} / \mathrm{s}$ in the sural nerve $(p=0.03)$. This was a consistent finding in both motor and sensory nerves in the lower limb.

Table 2. Nerve conduction velocities (NCV) and F-wave latencies in patients grouped according to their $\mathrm{HbA}_{1}$ value - changes during 8 years

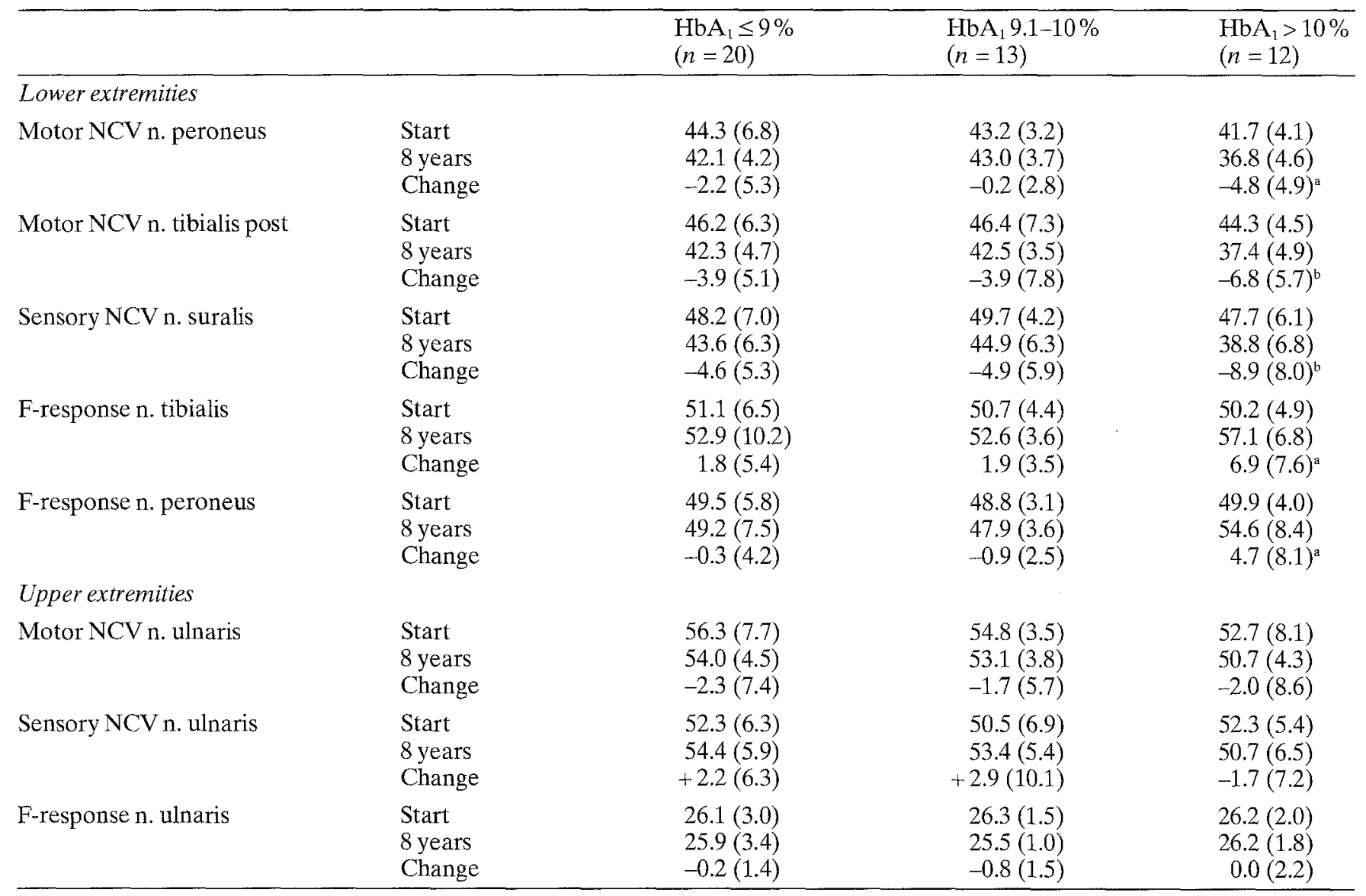

${ }^{\mathrm{a}} p<0.01{ }^{\mathrm{b}} p<0.05$ Patients with $\mathrm{HbA}_{1}>10 \%$ vs $\mathrm{HbA}_{1} \leq \quad$ Values are given as mean $( \pm \mathrm{SD})$ $10 \%$. 


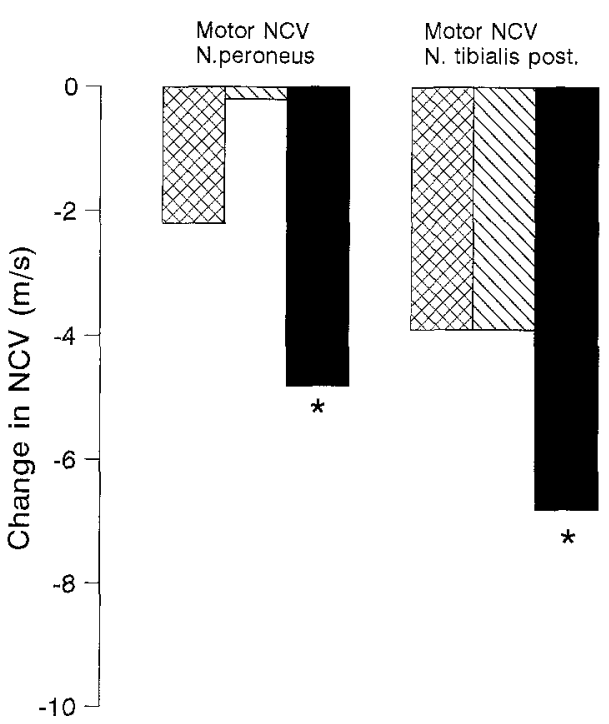

Sensory NCV N. suralis

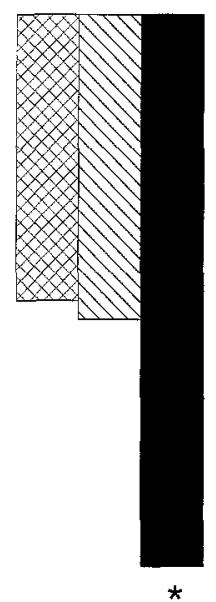

Fig. 1. Change of nerve conduction velocities (NCV) during 8 years in patients with $\mathrm{HbA}_{1}>10 \%, \mathrm{HbA}_{1} 9.1-10 \%$ and $\mathrm{HbA}_{1}<9 \%$

Table 3. Autonomic function tests at 8 years in patients grouped according to their $\mathrm{HbA}_{1}$ level

\begin{tabular}{|c|c|c|c|}
\hline & $\begin{array}{l}\mathrm{HbA}_{1}<9 \% \\
(n=19)\end{array}$ & $\begin{array}{l}\mathrm{HbA}_{1} 9.1-10 \% \\
(n=13)\end{array}$ & $\begin{array}{l}\mathrm{HbA}_{1}>10 \% \\
(n=12)\end{array}$ \\
\hline $\begin{array}{l}\text { Respiratory RR } \\
\text { variation } \\
\text { (beats per min) }\end{array}$ & $27.4(14.0)$ & $27.9(8.8)$ & $19.4(10.7)^{\mathrm{a}}$ \\
\hline $\begin{array}{l}\text { Valsalva manoeuvre } \\
\text { mean lengthening }\end{array}$ & $1.66(0.4)$ & $2.02(0.3)$ & $1.80(0.5)$ \\
\hline $\begin{array}{l}\text { Heart rate } \\
\text { response to } \\
\text { standing }\end{array}$ & & & \\
\hline $\begin{array}{l}15: 0 \text { ratio } \\
30: 15 \text { ratio }\end{array}$ & $\begin{array}{l}0.72(0.1) \\
1.20(0.1)\end{array}$ & $\begin{array}{l}0.74(0.1) \\
1.20(0.2)\end{array}$ & $\begin{array}{l}0.78(0.1)^{a . b} \\
1.11(0.1)^{a}\end{array}$ \\
\hline
\end{tabular}

${ }^{\mathrm{a}} p<0.01$ patients with $\mathrm{HbA}_{1}>10 \%$ vs $\mathrm{HbA}_{1} \leq 10 \%$

${ }^{\mathrm{b}}$ corrected for age

Autonomic nerve function was not examined at the start of this study. A cross-sectional analysis of the data at the 8-year follow-up showed a significantly lowered heart rate ( $R-R$ interval) variation during deep breathing $(p=0.03)$ and heart rate response to standing $(15: 0$ ratio $p=0.003$ and $30: 15$ ratio $p=0.01$ ) in the group of patients with a mean $\mathrm{HbA}_{1}$ greater than $10 \%$ compared to the group of patients with $\mathrm{HbA}_{1}$ less than $10 \%$ during the previous 8 years. There was no statistically significant difference in heart rate response to the Valsalva manoeuvre in these two groups (Table 3 ).

\section{Discussion}

The most important finding of the present study is that long-term reduction of mean blood glucose levels retards the deterioration of both motor and sensory nerve conduction velocity in the lower limbs of IDDM patients. The deterioration in nerve conduction velocity was marked in those with mean $\mathrm{HbA}_{1}$ of more than $10 \%$ during 8 years. The study thus supports the theory that hyperglycaemia represents an important factor in the pathogenesis of early diabetic neuropathy.

The relation between nerve conduction velocity and morphological changes in human diabetic neuropathy has been unclear. However, a strong correlation between morphological changes in sural nerve biopsies and nerve conduction velocity was recently reported by Veves et al.[21]. They concluded that conventionalelectrophysiological tests in the lower limb are reliable surrogate measures for structural abnormalities in early diabetic neuropathy. Changes in nerve conduction velocity in the presentstudy may reflect structural changes.

Previous studies of the development of diabetic neuropathy implicated disease duration, degree of hyperglycaemia, height, and possibly alcohol consumption [22] as risk factors. No alcohol abuse was registered in our patients. According to the present study mean $\mathrm{HbA}_{1}$ over 8 years is an independent predictor for deterioration of nerve conduction velocity. Remarkably the change of nerve conduction velocity was not correlated with duration of diabetes, a well-established risk factor. This underlines the importance of hyperglycaemia in the development of early diabetic neuropathy, a risk factor that is accessible for intervention. Our findings suggest that strict glycaemic control with $\mathrm{HbA}_{1}$ levels less than $10 \%$ retards the progression of early diabetic neuropathy and that a $1 \%$ change of $\mathrm{HbA}_{1}$ will on average result in a $1.3 \mathrm{~m} / \mathrm{s}$ change of nerve conduction velocity over 8 years. In this intervention study mean $\mathrm{HbA}_{1}$ improved significantly by $1.7 \%$, suggesting that mean reduction of nerve conduction velocity was delayed by $2.2 \mathrm{~m} / \mathrm{s}$ compared to the patients with $\mathrm{HbA}_{1}$ over $10 \%$. This difference is within the range of what has been suggested as clinically important in a previous study by Dyck and O'Brien [23].

A significant deterioration of motor and sensory nerve conduction velocities in the lower limb was only found in the group of patients with $\mathrm{HbA}_{1}$ greater than $10 \%$. This group of patients also had significantly delayed F-responses in the posterior tibial and peroneal nerves and significantly reduced sensory nerve action potential amplitude in the sural nerve. There is high consistency in the findings even when taking into consideration that $\mathrm{F}$-wave latency may show some variability between examinations [24]. We found no significant electrophysiological changes in the upper limb.

In patients with diabetes of long duration structural degeneration of peripheral nerves, affecting both myelin and axons is common $[3,25,26]$. This stresses the importance of early treatment which can influence and retard these structural changes. Experimental data indicate that normalization of both nerve conduction velocity and morphological changes may occur in early stages of diabetic neuropathy [27]. 
Improvement of nerve conduction velocity has been reported following short-term insulin treatment in early diabetes $[12,28,29]$ and in patients with clinical or symptomatic neuropathy treated with continuous subcutaneous insulin infusion [30-34]. These rapidly reversible changes may have a different pathogenesis with metabolic dysfunction without development of persisting morphological changes [2]. The beneficial effect of near-normoglycaemia on peripheral nerve function in our patients has been demonstrated in previous results from the Oslo Study $[19,35]$ where a significant improvement of motor nerve conduction velocity on continuous subcutaneous insulin infusion was shown in all nerves tested, compared to conventional treatment. Sensory nerve conduction velocity and sensory nerve action potential amplitude improved slightly in all groups, the improvement being most prominent on continuous subcutaneous insulin infusion. The present results after 8 years strengthen our previous conclusions $[19,35]$. The beneficial effect of strict glycaemic control has recently been convincingly demonstrated in the Stockholm Study [36] and the Diabetes Control and Complication Trial (DCCT) [37].

Diabetic autonomic neuropathy is common, but symptomatic manifestations are surprisingly rare. Measurable autonomic defects may be found in as many as one-sixth of all patients [38]. A significant correlation between $\mathrm{HbA}_{1}$ level and autonomic dysfunction was demonstrated in the present study. Previous studies demonstrated a deterioration of heart rate variation at rest, during deep breathing, and while standing for patients on conventional insulin therapy compared with patients on continuous subcutaneous insulin infusion with improved glycaemic control [39]. This was recently confirmed by the DCCT [37].

Our neurophysiological findings are analogous to what we have reported regarding nephropathy and retinopathy [6,7]. Retinopathy worsened in patients with $\mathrm{HbA}_{1}$ greater than $10 \%$ compared to patients with $\mathrm{HbA}_{1}$ less than $10 \%$, and urinary albumin excretion improved in patients with $\mathrm{HbA}_{1}$ less than $8.5 \%$ and worsened in patients with $\mathrm{HbA}_{1}$ over $10 \%$. Our results may point to a common mechanism of microangiopathy for the development of neuropathy. There is increasing evidence in the literature that peripheral diabetic neuropathy may at least in part be due to endoneurial vessel disease $[40,41]$.

In conclusion the present study strongly suggests that chronic hyperglycaemia represents a main pathogenetic factor in subclinical diabetic neuropathy and that long-term lowering of blood glucose levels retards the development and progression of early diabetic neuropathy.

Acknowledgements. This study was supported by grants from the Norwegian Diabetes Association, the University of Oslo, the Norwegian Council of Cardiovascular Diseases, Jahres Medical Foundation, the Norwegian Council for Science and the Humanities, Novo Nordisk, and Aker Diabetes Research Fund.

\section{References}

1. Brown MJ, Ashbury AK (1984) Diabetic neuropathy. Ann Neurol 15: 2-12

2. Brown MJ, Greene DA (1984) Diabetic neuropathy: pathophysiology and management. In: Asbury AK, Gilliat RW (eds) Peripheral nerve disorders. Butterworth \& Co, London, pp 126-153

3. Thomas PK, Eliassen SG (1984) Diabetic neuropathy. In: Dyck PJ, Thomas PK, Lambert EH, Bunge R (eds) Peripheral neuropathy. 2 nd edn. Saunders, Philadelphia, pp 17731810

4. Boulton AJM, Worth RC, Druru J et al. (1984) Genetic and metabolic studies in diabetic neuropathy. Diabetologia 26: 15-19

5. Pirart J (1987) Diabetes mellitus and its degenerative complications: prospective study of 4400 patients observed between 1947 and 1973. Diabetes Care 1: 168-188

6. Dahl-Jørgensen K, Bjøro T, Kjerulf P, Sandvik L, Bangstad HJ, Hanssen KF (1992) The effect of long term strict glycemic control on kidney function in insulin-dependent diabetes mellitus: seven year results from the Oslo Study. Kidney Int 41: 920-923

7. Brinchmann-Hansen O, Dahl-Jørgensen K, Sandvik L, Hanssen KF (1992) Blood glucose concentrations and progression of diabetic retinopathy: the seven year results of the Oslo study. BMJ 304: 19-22

8. Hanssen KF, Bangstad H-J, Brinchmann-Hansen O, DahlJørgensen K (1992) Blood glucose control and diabetic microvascular complications: long-term effects of near-normoglycaemia. Diabetic Med 9: 697-705

9. Reichard P, Berglund B, Britz A, Cars I, Nilsson BY, Rosenqvist U (1991) Intensified conventional insulin-treatment retards the microvascular complications of insulin-dependent diabetes mellitus (IDDM): the Stockholm Diabetes Intervention Study (SDIS) after 5 years. J Intern Med 230: 101-108

10. Unger RH (1982) Meticulous control of diabetes: benefits, risks, and precautions. Diabetes 31: 479-483

11. Committee on Health Care Issues (1986) Does improved control of glycemia prevent or ameliorate diabetic polyneuropathy ? Ann Neurol 19: 288-290

12. Ward JD, Barnes CG, Fisher DJ, Baker RW (1971) Improvement in nerve conduction following treatment in newly diagnosed diabetics. Lancet I: $428-430$

13. Halar EM, Graf RJ, Halter JB, Brozovich FV, Soine TL (1982) Diabetic neuropathy: a clinical, laboratory and electrodiagnostic study. Arch Phys Med Rehabil 63: 298-303

14. Holman RR, Dornan TL, Mayon-White V et al. (1983) Prevention of deterioration of renal and sensory-nerve function by more intensive management of insulin-dependent diabetic patients: a two-year randomised prospective study. Lancet I: 204-208

15. Fedele D, Negrin P, Cardone Cet al. (1984) Influence of continuous subcutaneous insulin infusion (CSSI) treatment on diabetic somatic and autonomic neuropathy. $J$ Endocrinol Invest 7: 623-628

16. Service FJ, Rizza RA, Daube JR, O'Brien PC, Dyck PJ (1985) Near normoglycaemia improved nerve conduction and vibration sensation in diabetic neuropathy. Diabetologia 28: 722-727

17. Ehle AL, Raskin P (1986) Increased nerve conduction in diabetics after a year of improved giucoregulation. J Neurol Sci 74: 191-197

18. Warnmoltz JR, Mendell JR, O'Dorisio TM, Cataland S (1987) Comparison of the effects of continuous subcutaneous infusion and split-mixed injection of insulin on nerve function type I diabetes mellitus. J Neurol Sci 82: 161-169 
19. Dahl-Jørgensen K, Brinchmann-Hansen O, Hanssen KF et al. (1986) Effect of near normoglycaemia for two years on progression of early diabetic retinopathy, nephropathy, and neuropathy: the Oslo study. BMJ 293: 1195-1199

20. Ewing DJ, Clarke BF (1982) Diagnosis and management of diabetic autonomic neuropathy. BMJ 285: 916-918

21. Veves A, Malik RA, Lye RH et al. (1991) The relationship between sural nerve morphometric findings and measures of peripheral nerve function in mild diabetic neuropathy. Diabetic Med 8: 917-921

22. Mc Culloch DK, Campbell IW, Prescott RJ, Clarke BF (1980) Effect of alcohol intake on symptomatic peripheral neuropathy in diabetic men. Diabetes Care 3: 245-247

23. Dyck PJ, O'Brien PC (1989) Meaningful degrees of prevention or improvement of nerve conduction in controlled clinical trials of diabetic neuropathy. Diabetes Care 12: 649-652

24. Young RR, Shahani BT (1978) Clinical value and limitation of F-wave determination. Muscle Nerve 1:248-249

25. Behse F, Buchtal F, Carlsen F (1977) Nerve biopsy and conduction studies in diabetic neuropathy. J Neurol Neurosurg Psych 40: 1072-1082

26. Dyck PJ, Sherman WR, Hallcher LM et al. (1980) Human diabetic endoneurial sorbitol, fructose, and myo-inositol related to sural nerve morphometry. Ann Neurol 8:590-596

27. Sima AAF, Brismar T (1985) Reversible diabetic nerve dysfunction: structural correlates to electrophysiological abnormalities. Ann Neurol 18: 21-29

28. Gregersen G (1986) Variation in motor conduction velocities produced by acute changes in the metabolic state in diabetic patients. Diabetologia 4: 273-277

29. Gregersen G (1967) Diabetic neuropathy: influence of age, sex, metabolic control, and duration of diabetes on motor conduction velocity. Neurology 17: 972-979

30. Boulton AJM, Drury J, Clarke B, Ward JD (1982) Continuous subcutaneous insulin infusion in the management of painful diabetic neuropathy. Diabetes Care 5: 386-390

31. Pietri A, Ehle Al, Raskin P (1980) Changes in nerve conduction velocity after six weeks of glucoregulation with portable insulin infusion pumps. Diabetes 29: 668-671
32. Gambardella S, Napoli A, Spallone V et al. (1983) Influence of glucoregulation with continuous subcutaneous insulin infusion on nerve conduction velocity and beat to beat variation in diabetics. $J$ Endocrinol Invest $6: 363-367$

33. Warnmoltz JS, Mendell JR, O'Dorisio TM, Catland S (1981) Evaluation of portable infusion pump on peripheral nerve function in diabetes mellitus. Neurology 31: 129-133

34. Hamet P, Abarca G, Lopez D et al. (1982) Patient self-management of continuous subcutaneous insulin infusion. Diabetes Care 5: 485-491

35. Dahl-Jørgensen K (1987) Near normoglycemia and late diabetic complications. The Oslo study (Thesis). Acta Endocrinol [Suppl 284]

36. Reichard P, Nilsson B-Y, Rosenqvist U (1993) The effect of long-term intensified insulin treatment on the development of microvascular complications of diabetes mellitus. NEngl J Med 329:304-309

37. The Diabetes Control and Complications Trial Research Group (1993) The effect of intensive treatment of diabetes on the development and progression of long-term complications in insulin-dependent diabetes mellitus. N Engl J Med 329: 977-986

38. O'Brien IAD, O'Hare JP, Lewin IG, Corrall RJM (1986) The prevalence of autonomic neuropathy in insulin-dependent diabetes mellitus: a controlled study based on heart rate variability. Q J Med 61: 951-967

39. Jakobsen J, Christiansen JS, Kristoffersen J et al. (1988) Autonomic and somatosensory nerve function after 2 years of continuous subcutaneous insulin infusion in type I diabetes. Diabetes 37: 452-455

40. Malik RA, Newrick PG, Sharma AK et al. (1989) Microangiopathy in human diabetic neuropathy: relationship betweeen capillary abnormalities and the severity of neuropathy. Diabetologia 32: 92-102

41. Tesfaye S, Harris ND, Wilson RM, Ward JD (1992) Exerciseinduced conduction velocity increment: a marker of impaired peripheral nerve blood flow in diabetic neuropathy. Diabetologia 35: 155-159 